\title{
KONTRIBUSI LEMBAGA KEUANGAN MIKRO SYARIAH TERHADAP PEMBERDAYAAN PEREMPUAN (STUDI KASUS BMT DI KABUPATEN SLEMAN YOGYAKARTA)
}

\author{
Ninik Sri Rahayu \\ Rr. Sita D. Kusumaningrum \\ Pusat Studi Gender Universitas Islam Indonesia \\ Email: ninik.srirahayu2013@gmail.com
}

\begin{abstract}
ABSTRAK
Penelitian ini bertujuan untuk menggali bagaimana kontribusi lembaga keuangan mikro syariah terhadap pemberdayaan perempuan. Penelitian ini melibatkan lima BMT di Kabupaten Sleman dengan kriteria lama operasional lebih dari 5 tahun. Populasi dan sampel penelitian adalah perempuan pengusaha mikro yang menjadi anggota lembaga keuangan mikro (BMT) minimal dua tahun. Metode sampel yang ditempuh dalam penelitian ini adalah sampel daerah multitahap (Multistage Area Sampling). Variabel dependen dalam penelitian ini meliputi Kontrol atas tabungan dan pendapatan, Kepemilikan, Pengambilan Keputusan, Self-efficacy, Self-esteem, Mobilitas dan partisipasi dalam kegiatan di luar rumah.

Penelitian ini menghasilkan beberapa temuan antara lain I) Secara statistik terdapat perbedaan signifikan kontrol tabungan dan pendapatan usaha, pengambilan keputusan, mobilitas dan partisipasi antara perempuan yang menjadi anggota BMT dan nonBMT. 2) Hasil pengujian Mann Whitney $U$ menunjukan tidak ada perbedaan self efficacy dan self esteem antara perempuan yang menjadi anggota BMT dan perempuan nonanggota BMT.

Riset merekomendasika beberapa hal yakni I) Penelitian berikutnya perlu menambah jumlah minimal responden sehingga temuan penelitian lebih mewakili situasi yang sebenarnya. 2) Segmen terbesar dari BMT adalah pedagang atau pengusaha mikro perempuan. Oleh karena itu, adalah penting bagi BMT untuk memiliki program-program yang berorientasi pada pemberdayaan perempuan. 3) Penelitian berikutnya perlu melihat bagaimana dampak BMT terhadap relasi gender dalam rumah tangga dan implikasinya terhadap perempuan. Hal ini penting mengingat dalam kultur masyarakat Indonesia khususnya Yogyakarta, praktek-praktek patriarkhis masih cukup kuat berakar
\end{abstract}

Kata Kunci : Pemberdayaan perempuan, lembaga Keuangan Mikro, BMT.

\section{ABSTRACT}

This study aims at exploring the contribution of Sharia Microfinance Institution (Baitul Maal wat Tamwil-BMT) on women empowerment using quantitative as well as qualitative method of analysis. There are five BMTs in Kabupaten Sleman that have been operating more than five years used as the population of study. In more detail, this study takes microentrepreneurs women who have been joining BMT minimal for two years as the samples of study by using Multistage Area 
Sampling Methods. The dependent variables consist of control over saving and income, ownership, decision-making, self-efficacy, self-esteem, mobility, and participation of activities outside home.

The statistical analysis using Mann Whiteney $U$ Test results in two research findings, namely I) This study shows a significant difference on control over savings and income, decision-making, mobility, and participation of activities outside home between women members of BMTs and nonmembers. 2) This study shows no significant difference on self-efficacy and self-esteem between women members of BMTs and non-members.

Based on research findings, this study recommends several points, namely I) it is necessary for the next research to increase the minimal number of respondent so that they can represent the real situation. 2) The biggest segments of BMTs are merchants/traders as well as microentrepreneurs women. Therefore, it is important for BMTs to develop more women empowerment oriented programs. 3) The next research should explore the impact of BMTs on gender relation in the family and its implication for women. This is important since in the culture of Indonesian society, especially in Yogyakarta, the practices of patriarchy are still firmly rooted

Keywords: Empowerment, Women, BMT

\section{PENDAHULUAN}

Praktik di banyak negara berkembang menunjukan bahwa lembaga keuangan mikro merupakan alat intervensi paling efektif untuk pengentasan kemiskinan di kalangan perempuan. Langkah afirmatif yang digagas peraih nobel Ekonomi M. Yunus dari Bangladesh untuk mendirikan bank yang propoor dan progender bernama Grameen Bank, terbukti mampu mendorong 58 persen peminjamnya keluar dari garis kemiskinan. Eksperimen yang dilakukan Grameen Bank ini patut ditimbang sebagai satu alternatif metodologis untuk mengentaskan kantung-kantung kemiskinan di Indonesia, yang didominasi oleh wajah perempuan (poverty feminization).

Perempuan adalah lapisan termiskin dari yang paling miskin (the poorest of the poor). Tidak hanya miskin dari sisi ekonomi, tetapi juga miskin jika ditinjau dari pemenuhan kebutuhan dasarnya seperti kebutuhan sosial, kesehatan, dan politik. Mayoritas perempuan miskin terserap di sektor informal sebagai buruh tani, buruh pabrik, pekerja rumah tangga dan pedagang kecil. Kelompok ini sulit mendapatkan akses terhadap berbagai sumber daya termasuk layanan keuangan. Kredit perbankan merupakan salah satu mata ratai yang terputus dalam kehidupan perempuan. Entitas ini dianggap sebagai segmen yang tidak layak untuk didanai karena umumnya pinjaman yang diajukan terlalu kecil, tidak bankable.

Akses perbankan menjadi kian jauh dari perempuan karena berbagai aturan yang netral gender. Skim kredit yang mensyaratkan pembiayaan harus menyertakan agunan sulit dipenuhi perempuan, karena penguasaan atas berbagai sumber daya seperti tanah, rumah, dan aset lain secara kultural berada di bawah kontrol dan penguasaan laki-laki. Studi yang dilakukan oleh Kato dan Kratzer (2013) di Tanzania memperlihatkan bahwa perempuan yang memanfaatkan layanan lembaga keuangan mikro lebih berdaya dibanding mereka yang tidak berpartisipasi di dalamnya. ILO (1998) juga menyakini jika microfinance berdampak positif terhadap perbaikan kehidupan perempuan dalam hal peningkatan pendapatan, status gizi dan kesehatan, pendidikan anak, dan penciptaan lapangan kerja di sektor mikro bagi perempuan lain. Keyakinan tersebut didukung temuan empiris dari Khan dan Noreen (2012) yang menyatakan adanya korelasi positif antara lembaga keuangan mikro dan pemberdayaan perempuan. 
Penelitian ini bertujuan untuk menggali bagaimana kontribusi lembaga keuangan mikro syariah terhadap pemberdayaan perempuan. Signifikasi dari penelitian ini terletak pada dua hal. Pertama, kajian mengenai lembaga keuangan mikro syariah dan pemberdayaan perempuan masih sangat terbatas, mayoritas studi sebelumnya berfokus pada lembaga keuangan mikro konvensional. Kedua, Lembaga keuangan mikro syariah menawarkan solusi alternatif pengurangan kemiskinan melalui skema finansial yang lebih berorientasi pada pengembangan kapasitas umat sebagai konsekuensi penerapan nilai-nilai Islam yang mempromosikan keadilan sosial tanpa memandang perbedaan gender, usia, dan suku. Ketiga, perkembangan lembaga keuangan mikro syariah di Indonesia selama 10 tahun terakhir cukup pesat terutama Baitul Maal wat Tamwil (BMT).

Rumusan masalah dari riset ini adalah: "Bagaimana kontribusi Lembaga Keuangan Mikro Syariah (BMT) di Kabupaten Sleman terhadap pemberdayaan perempuan?"

\section{Penelitian Terdahulu}

Berbagai riset mendokumentasikan bahwa lembaga keuangan mikro memiliki spektrum luas dalam memampukan perempuan. Studi Kabeer (2001) menemukan jika program pembiayaan dari lembaga keuangan mikro berdampak signifikan terhadap delapan dimensi pemberdayaan perempuan. Kajian tersebut berkesimpulan bahwa akses terhadap kredit merupakan penentu signifikan dalam penguatan ekonomi perempuan berupa penambahan aset yang dimiliki atas nama perempuan, peningkatan daya beli, kesadaran politik dan hukum, dan semakin baiknya indeks keberdayaan. Penelitian Pitt and Khandker (1998) di Bangladesh memperlihatkan bahwa program kredit berimbas nyata pada pola perilaku perempuan miskin, dimana pengeluaran konsumsi meningkat 0,22 Dollar apabila jumlah pembiayaan yang mereka ambil dari bank bertambah 1,22 Dollar, dibanding peminjam laki-laki yang hanya naik 0,13 Dollar. Mahmud (2003), membuktikan jika partisipasi perempuan dalam program kredit mikro menaikan tingkat kesejahteraan sekaligus mengurangi kesenjangan penghasilan dengan laki-laki. Lebih lanjut, MkNelly dan Watetip (1993) mengemukakan kredit mikro mampu meningkatkan kepercayaan diri perempuan dan menjadikan relasi dengan tetangga menjadi lebih positif. Kato dan Kratzer (2013) menemukan bahwa partisipasi perempuan dalam keuangan mikro meningkatkan keberdayaan mereka sehingga mereka mampu membuat pilihan dan mengambil keputusan terkait kesejahteraan personal dan anak-anaknya.

Penelitian ini bertujuan untuk menindaklanjuti dan mengembangkan temuan riset terdahulu dengan menganalisis seberapa besar kontribusi lembaga keuangan mikro syariah dan pemberdayaan perempuan dalam konteks Indonesia. Dimensi pemberdayaan dalam penelitian ini mengacu pada kerangka yang dikembangkan oleh Kato dan Kratzer. Perbedaannya adalah, riset ini berfokus pada lembaga keuangan mikro syariah sementara riset sebelumnya menyasar lembaga keuangan mikro konvensional. Riset yang secara spesifik mengkaitkan BMT dengan pemberdayaan perempuan sangat jarang dilakukan, mengingat konsep pemberdayaan dalam BMT adalah pada pemberdayaan keluarga, bukan "women only approach" sebagaimana dalam institusi keuangan mikro konvensional. Namun, dalam konteks Indonesia, isu ini penting untuk diangkat paling tidak karena beberapa alasan; pertama BMT merupakan alternatif pengentasan kemiskinan dan 
perempuan adalah entitas paling miskin di antara kelompok miskin. Kedua, segmen BMT adalah pedagang dan pengusaha level mikro. Pada kenyataanya, satu per tiga dari usaha mikro di Indonesia dimiliki oleh perempuan. Akses terhadap sumber keuangan formal merupakan salah satu isu bagi mereka. Ketiga, terdapat fenomena peningkatan jumlah perempuan kepala keluarga. BPS menyebutkan bahwa 14 persen dari rumah tangga di Indonesia dikepalai oleh perempuan dan mayoritas adalah keluarga miskin yang menggantungkan hidupnya dari usaha informal (mikro).

\section{LANDASAN TEORI \\ Pengertian Lembaga Keuangan Mikro Syariah}

Perkembangan Lembaga Keuangan

Mikro Syariah (LKMS) di Indonesia mengalami peningkatan yang siginifikan selama 10 tahun terakhir seiring pesatnya pertumbuhan perbankan syariah. LKMS berperan vital dalam menggerakan roda perekonomian dengan menggarap segmen lapisan ekonomi terbawah yang tidak dapat diakomodasi oleh perbankan secara umum. LKMS didefinisikan sebagai lembaga keuangan yang kegiatanya menghimpun dan menyalurkan dana masyarakat yang bersifat profit atau lembaga keuangan syariah nonperbankan yang bersifat informal. Disebut informal karena lembaga ini didirikan oleh masyarakat, berbeda dengan lembaga kuangan perbankan dan lembaga keuangan lainnya. Salah satu lembaga keuangan mikro syariah yang paling populer saat ini adalah BMT (Baitul Maal wat Tamwil). Secara nasional, jumlah BMT yang beroperasi di seluruh Indonesia berjumlah 3.500 unit. Angka tersebut masih berpeluang untuk terus bertambah mengingat kegiatan bisnis BMT rata-rata per tahun naik sebesar 40-50 persen (Haryadi, 2014).

\section{Pengertian dan Peran BMT}

BMT (Baitul Maal wat Tamwil) adalah Lembaga Keuangan Mikro Syariah yang dioperasikan dengan prinsip bagi hasil, misinya adalah menumbuh kembangkan bisnis usaha mikro dan kecil dalam kerangka mengangkat derajat dan martabat serta membela kepentingan kaum fakir miskin. Pengertian lain dari Maal wat Tamwil (BMT) adalah lembaga keuangan syariah informal yang didirikan sebagai pendukung dalam meningkatkan kualitas usaha ekonomi pengusaha mikro dan pengusaha kecil bawah berlandaskan sistem syariah.

\section{Pemberdayaan Perempuan Konsep Pemberdayaan}

Secara etimologis, pemberdayaan berasal dari kata dasar "daya" yang berarti kekuatan atau kemampuan. Bertolak dari pengertian tersebut, maka pemberdayaan dimaknai sebagai proses untuk memperoleh daya, kekuatan atau kemampuan, dan atau pemberian daya, kekuatan atau kemampuan dari pihak yang memiliki daya kepada pihak yang kurang atau belum berdaya (Sulistiyani, 2004). Sementara menurut Prijono dan Pranarka (1996), pemberdayaan adalah proses kepada masyarakat agar menjadi berdaya, mendorong atau memotivasi individu agar mempunyai kemampuan atau keberdayaan untuk menentukan pilihan hidupnya dan pemberdayaan harus ditujukan pada kelompok atau lapisan masyarakat yang tertinggal.

Dalam konteks pemberdayaan perempuan, Nursahbani Katjasungkana dalam diskusi Tim Perumus Strategi Pembangunan Nasional (Nugroho, 2008) mengemukakan, ada empat indikator pemberdayaan yakni: 1) Akses, dalam arti kesamaan hak dalam mengakses sumber daya-sumber daya produktif di dalam lingkungan. 2) Partisipasi, yaitu keikutsertaan dalam mendayagunakan aset atau sumber daya yang terbatas 
tersebut. 3) Kontrol, yaitu bahwa lelaki dan perempuan mempunyai kesempatan yang sama untuk melakukan kontrol atas pemanfaatan sumber daya-sumber daya tersebut. 4) Manfaat, yaitu bahwa lelaki dan perempuan harus sama-sama menikmati hasil-hasil pemanfaatan sumber daya atau pembangunan secara bersama dan setara.

\section{Kerangka Pikir dan Pengembangan Hipotesis}

Studi ini mengadopsi framework yang dikembangkan oleh Kato and Kratzer (2013) untuk menjelaskan dampak lembaga keuangan mikro syariah terhadap pemberdayaan perempuan. Menurut Kabeer (2001) konsep pemberdayaan berkaitan dengan kemampuan seseorang untuk membuat pilihan strategi hidup dimana kemampuan tersebut sebelumnya secara kultural tidak memungkinkan untuk dilakukan. Konsep tersebut berkait dengan bagaimana keluar dari "ketidakberdayaan" menuju situasi yang membuat mereka lebih berdaya dan mampu membuat keputusan strategis dalam hidupnya. Dalam konteks ini, pemberdayaan (empowerment) dapat menjadi sumber daya (resources), agensi (agency), sekaligus pencapaian (achievement). Sumber daya tersebut dapat bersifat material atau sosial. Agency merupakan sentral dari keseluruhan proses yang dapat dimaknai sebagai kemampuan untuk mendifinisikan tujuan dan strategi untuk mencapainya.

Konsep dan indikator pemberdayaan dalam penelitian ini mengacu pada framework yang dikembangkan oleh Malhotra dan Schuler (2002) yakni mencakup aspek: kontrol terhadap tabungan dan pendapatan, kepemilikan aset, pengambilan keputusan, mobilitas, self-efficacy and self-esteem.

Kontribusi lembaga keuangan mikro syariah (BMT) terhadap pemberdayaan perempuan, dijelaskan dalam kerangka pikir sebagai berikut:
Situasi perempuan pengusaha mikro di Yogykarta secara umum: akses, kontrol, dan partisipasi terhadap sumber daya produktif terbatas (terutama finansial)

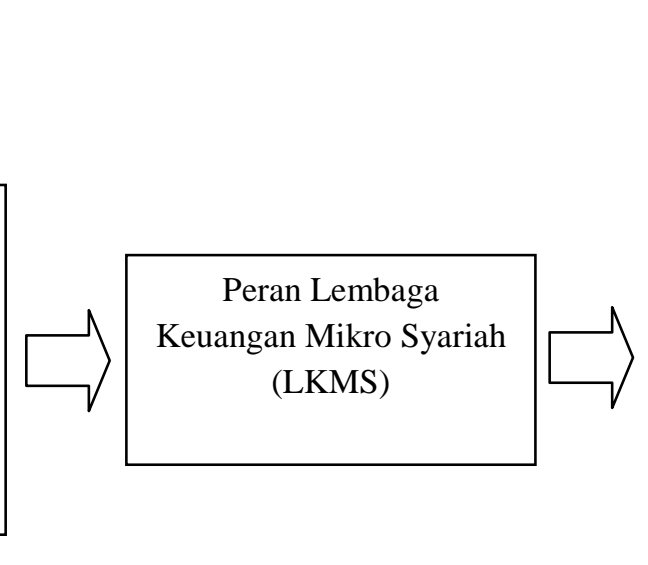

Gambar 1: Kerangka Pikir
Kontribusi LKMS terhadap pemberdayaan perempuan Indikator:

- Adanya kontrol terhadap tabungan dan investasi

- Peningkatan kepemilikan aset

- Partisipasi dalam pengambilan keputusan

- Peningkatan mobilitas dan kegiatan luar rumah

- Peningkatan harga diri

- Peningkatankeyakinan diri
Perempuan diasumsikan akan lebih berdaya jika berpartisipasi dalam layanan lembaga keuangan mikro syariah dibanding yang tidak berpartisipasi. Hal ini karena mereka berpeluang untuk memperoleh pendapatan melalui berbagai aktifitas ekonomi produktif yang pada akhirnya akan meningkatkan kontribusi mereka terhadap pemenuhan kebutuhan keluarga, akses dan peran terhadap pengambilan keputusan serta kontrol terhadap alokasi sumber daya yang dimiliki oleh keluarga. 
H1: Perempuan yang berpartisipasi dalam layanan lembaga keuangan mikro syariah memiliki kontrol lebih besar terhadap tabungan dan keuntungan usaha dibanding yang tidak berpartisipasi.

H2: Perempuan yang berpartisipasi dalam layanan lembaga keuangan mikro memiliki kesempatan lebih besar untuk terlibat dalam proses pengambilan keputusan keluarga dibanding yang tidak berpartisipasi.

Keuntungan usaha yang diperoleh melalui pemanfaatan pembiayaan dari lembaga keuangan mikro dan pengelolaan manajemen keuangan yang lebih baik menjelaskan bahwa perempuan mampu melakukan perencanaan pengeluaran yang berdampak terhadap kepemilikan aset (Barnes \& Nemarundwe, 2001).

H3: Partisipasi perempuan dalam layanan lembaga keuangan mikro syariah berdampak signifikan terhadap kepemilikan properti dan aset dibanding yang tidak berpartisipasi.

Hunt dan Kasyanathan (2001) menemukan bahwa hal yang paling bernilai bagi perempuan terkait keterlibatanya dalam lembaga keuangan mikro adalah aspek kepercayaan diri (confidence), pengetahuan (knowledge) dan pelatihan (training) yang mereka peroleh. Beberapa perempuan yang tergabung dalam kelompok pembiayaan mengatakan dapat mengambil tindakan perlawanan ketika berhadapan dengan situasi yang menyulitkan mereka. Ini mengindikasikan bahwa layanan lembaga keuangan mikro meningkatkan selfesteem dan self efficacy yang mendorong peningkatan peran aktif dalam pengambilan keputusan baik di dalam rumah tangga maupun dalam komunitas.

H4: Partisipasi dalam lembaga keuangan mikro syariah berdampak signifikan terhadap peningkatan self esteem perempuan dibanding mereka yang tidak terlibat.
H5: Partisipasi dalam lembaga keuangan mikro syariah berdampak signifikan terhadap peningkatan selfefficacy perempuan dibanding mereka yang tidak terlibat.

Mayoux (1999) menyatakan bahwa program lembaga keuangan mikro berkontribusi terhadap perubahan peran gender. Perempuan yang sebelumnya tidak memiliki akses terhadap pendapatan kemudian mampu mengembangkan aktifitas ekonomi produktif sehingga mereka menjadi lebih mobile dan bertambah wawasannya.

H6: Partisipasi dalam Lembaga Keuangan Mikro Syariah meningkatkan mobilitas dan aktifitas perempuan di luar rumah dibanding mereka yang tidak terlibat.

\section{METODE PENELITIAN \\ Sampel dan Populasi}

Populasi dan sampel penelitian adalah perempuan pengusaha mikro yang menjadi anggota lembaga keuangan mikro (BMT) di Kabupaten Sleman. Pemilihan lokasi didasarkan pada pertimbangan jumlah BMT di Sleman lebih banyak dibanding Kabupaten lain di Yogyakarta, kurang lebih 54 unit (data tahun 2012) sehingga bisa diasumsikan jumlah perempuan yang terlayani oleh lembaga keuangan ini cukup banyak.

\section{Metode Sampling}

Metode sampel yang ditempuh dalam penelitian ini adalah sampel daerah multitahap (Multistage Area Sampling). Multistage Area Sampling adalah prosedur pengambilan sampel yang melibatkan penggunaan kombinasi teknik sampel probabilitas (Kuncoro:2003). Tahap-tahap pengambilan adalah sebagai berikut: 1) Menentukan jumlah BMT sebagai sampel. Penelitian ini akan mengambil sampel sebanyak 10 persen dari total populasi atau sebanyak 5 BMT dengan metode purposive random sampling. 2) Minimal 
sepuluh persen anggota perempuan dijadikan sebagai sampel penelitian. Responden yang dipilih adalah yang sudah menjadi anggota BMT minimal 2 tahun. Penelitian ini juga akan mengambil sampel perempuan pengusaha mikro yang tidak menjadi anggota BMT sebagai variabel kontrol. Proses seleksi akan dilakukan secara random.

\section{Variabel Penelitian dan Operasionalisasi}

Terdapat 6 variabel yang akan digunakan dalam penelitian ini yaitu: 1) Kontrol atas tabungan dan pendapatan: Diukur dari peningkatan peran dan daya tawar dalam pengambilan keputusan khususnya mengenai keputusan untuk menyimpan dan penggunaan pendapatan yang diperoleh atau dihasilkan dari kegiatan usaha. 2) Kepemilikan: Mengacu pada penguasaan individu dan rumah tangga atas properti dan aset berdasarkan kepemilikan secara legal dan formal. 3) Pengambilan keputusan: Diukur melalui: siapa yang membuat keputusan mengenai pembelian dan investasi dalam rumah tangga. 4) Selfefficacy: Variabel ini merefleksikan bagimana artikulasi dan kepercayaan diri perempuan ketika berbicara di depan publik dengan banyak pihak seperti misalnya pemilik otoritas atau guru dari anak-anaknya. 5) Self-esteem: Diukur melalui: apakah perempuan membuat kontribusi besar terhadap keluarga, komunitas, dan bagaimana mereka mengevaluasi diri mereka sendiri jika dibandingkan dengan laki-laki dan kelompok lain dalam masyarakat. 6) Mobilitas dan Partisipasi dalam kegiatan di luar rumah : Berkaitan dengan keleluasaan perempuan tanpa merasa khawatir dan terhalangi, terutama jika harus berpergian jauh sendiri sedangkan partisipasi diukur dari keterlibatan perempuan pada aktivitas di luar rumah.

\section{Teknik Analisa Data dan Teknik Analisa Data}

Pengumpulan data dilakukan melalui dua cara, yaitu kuesioner dan wawancara mendalam. Untuk melakukan pengujian hipotesis uji nonparametric Mann-Whitney $U$ test digunakan untuk menentukan apakah ada perbedaan signifikan antara perempuan yang menjadi anggota lembaga keuangan mikro syariah dan yang tidak menjadi anggota. Mann Whitney $U$ test adalah uji nonparametric yang digunakan untuk mengetahui perbedaan dua median kelompok bebas apabila skala data variabel terikatnya adalah ordinal atau interval/ratio tetapi tidak berdistribusi normal.

\section{Hasil Penelitian dan Pembahasan Gambaran Umum Responden}

Gambaran Umum responden penelitian terangkum dalam tabel berikut ini :

Tabel 1:Gambaran Umum Responden Penelitian

\begin{tabular}{|l|r|r|r|r|r|r|}
\hline \multirow{2}{*}{ Keterangan } & \multicolumn{2}{|c|}{ Anggota } & \multicolumn{2}{c|}{ NonAnggota } & \multicolumn{2}{c|}{ Total } \\
\cline { 2 - 7 } & \multicolumn{1}{|c}{$\mathbf{n}$} & \multicolumn{1}{c|}{ \% } & \multicolumn{1}{c|}{$\mathbf{n}$} & \% & $\mathbf{n}$ & $\%$ \\
\hline Usia (tahun) & & & & & & \\
$\leq 29$ & 5 & 5 & 2 & 4 & 7 & 5 \\
30 s/d 39 & 20 & 20 & 13 & 26 & 33 & 22 \\
40 s/d 49 & 35 & 35 & 13 & 26 & 48 & 32 \\
50 s/d 59 & 33 & 33 & 14 & 28 & 47 & 31 \\
$\geq 60$ & 7 & 7 & 8 & 16 & 15 & 10 \\
Total & $\mathbf{1 0 0}$ & $\mathbf{1 0}$ & $\mathbf{1 0 0}$ & $\mathbf{1 0 0}$ & $\mathbf{1 5 0}$ & $\mathbf{1 0 0}$ \\
& & $\mathbf{0}$ & & & & \\
\hline
\end{tabular}




\begin{tabular}{|c|c|c|c|c|c|c|}
\hline \multicolumn{7}{|l|}{ Status Pernikahan } \\
\hline Menikah & 89 & 89 & 40 & 80 & 129 & 86 \\
\hline Janda & 11 & 11 & 10 & 20 & 21 & 14 \\
\hline Total & 100 & 10 & 50 & 100 & 150 & 100 \\
\hline & & 0 & & & & \\
\hline \multicolumn{7}{|l|}{ Pekerjaan Suami } \\
\hline Pegawai Negeri & 9 & 9 & 1 & 2 & 10 & 7 \\
\hline Pegawai Swasta & 9 & 9 & 4 & 8 & 13 & 9 \\
\hline Wiraswasta & 24 & 24 & 20 & 40 & 44 & 29 \\
\hline Pedagang & 12 & 12 & 0 & 0 & 12 & 8 \\
\hline Buruh & 19 & 19 & 6 & 12 & 25 & 17 \\
\hline Pensiunan & 3 & 3 & 2 & 4 & 5 & 3 \\
\hline Petani/Peternak & 5 & 5 & 6 & 12 & 11 & 7 \\
\hline Tidak Bekerja & 5 & 5 & 0 & 0 & 5 & 3 \\
\hline Lainnya & 14 & 14 & 11 & 22 & 25 & 17 \\
\hline Total & 100 & 10 & 50 & 100 & 150 & 100 \\
\hline & & 0 & & & & \\
\hline \multicolumn{7}{|l|}{ Jumlah Anak } \\
\hline 0 & 3 & 3 & 1 & 2 & 4 & 3 \\
\hline 1 & 17 & 17 & 7 & 14 & 24 & 16 \\
\hline 2 & 40 & 40 & 18 & 36 & 58 & 39 \\
\hline 3 & 25 & 25 & 7 & 14 & 32 & 21 \\
\hline 4 & 8 & 8 & 12 & 24 & 20 & 13 \\
\hline 5 & 6 & 6 & 3 & 6 & 9 & 6 \\
\hline$>5$ & 1 & 1 & 2 & 4 & 3 & 2 \\
\hline Total & 100 & 10 & 50 & 100 & 150 & 100 \\
\hline & & 0 & & & & \\
\hline \multicolumn{7}{|l|}{ Jenis Usaha } \\
\hline Perdagangan & 93 & 93 & 42 & 84 & 135 & 90 \\
\hline Jasa (Laundry, Catering, Jahit, Sablon) & 7 & 7 & 5 & 10 & 12 & 8 \\
\hline Wirausaha (Kerajinan) & 0 & 0 & 3 & 6 & 3 & 2 \\
\hline Total & 100 & 10 & 50 & 100 & 150 & 100 \\
\hline & & 0 & & & & \\
\hline \multicolumn{7}{|l|}{ Lama Usaha (tahun) } \\
\hline$<1$ & 0 & 0 & 0 & 0 & 0 & 0 \\
\hline $1 \mathrm{~s} / \mathrm{d}<2$ & 1 & 1 & 2 & 4 & 3 & 2 \\
\hline $2 s / d<5$ & 14 & 14 & 8 & 16 & 22 & 15 \\
\hline $5 \mathrm{~s} / \mathrm{d}<10$ & 16 & 16 & 16 & 32 & 32 & 21 \\
\hline $10 \mathrm{~s} / \mathrm{d}<20$ & 39 & 39 & 17 & 34 & 56 & 37 \\
\hline$\geq 20$ & 30 & 30 & 7 & 14 & 37 & 25 \\
\hline Total & 100 & 10 & 50 & 100 & 150 & 100 \\
\hline & & 0 & & & & \\
\hline \multicolumn{7}{|l|}{ Jumlah Karyawan } \\
\hline 0 & 76 & 76 & 38 & 76 & 114 & 76 \\
\hline $1 \mathrm{~s} / \mathrm{d} 2$ & 16 & 16 & 10 & 20 & 26 & 17 \\
\hline $3 \mathrm{~s} / \mathrm{d} 4$ & 7 & 7 & 2 & 4 & 9 & 6 \\
\hline
\end{tabular}




\begin{tabular}{|l|r|r|r|r|r|r|}
\hline$\geq 4$ & $\mathbf{1}$ & $\mathbf{1}$ & 0 & $\mathbf{0}$ & $\mathbf{1}$ & $\mathbf{1}$ \\
Total & $\mathbf{1 0 0}$ & $\mathbf{1 0}$ & $\mathbf{5 0}$ & $\mathbf{1 0 0}$ & $\mathbf{1 5 0}$ & $\mathbf{1 0 0}$ \\
\hline Omset Usaha (juta) & & $\mathbf{0}$ & & & & \\
$<$ Rp1 juta & 5 & 5 & 7 & 14 & 12 & 8 \\
Rp1 s/d < Rp5 & 50 & 50 & 25 & 50 & 75 & 50 \\
Rp5 s/d < Rp10 & 17 & 17 & 11 & 22 & 28 & 19 \\
Rp10 s/d < Rp20 & 10 & 10 & 3 & 6 & 13 & 9 \\
Rp20 s/d < Rp35 & 9 & 9 & 2 & 4 & 11 & 7 \\
Rp35 s/d < Rp55 & 0 & 0 & 1 & 2 & 1 & 1 \\
Rp55 s/d < Rp80 & 4 & 4 & 1 & 2 & 5 & 3 \\
$\geq$ Rp80 & 5 & 5 & 0 & 0 & 5 & 3 \\
Total & $\mathbf{1 0 0}$ & $\mathbf{1 0}$ & $\mathbf{5 0}$ & $\mathbf{1 0 0}$ & $\mathbf{1 5 0}$ & $\mathbf{1 0 0}$ \\
& & $\mathbf{0}$ & & & & \\
\hline
\end{tabular}

Sumber : Data Primer diolah kembali,2015

Secara keseluruhan karakteristik responden dalam penelitian ini adalah anggota BMT dan anggota nonBMT yang berusia 40 - 49 tahun dan 50 - 59 tahun, mayoritas telah menikah, suami bekerja sebagai wiraswasta, usaha yang ditekuni adalah sektor perdagangan, lama usaha berkisar 10 sampai dengan 20 tahun, tidak memiliki karyawan, dan omset perbulan dalam interval Rp.1000.000-Rp.5.000.000 per bulan.

\section{Hasil dan Pembahasan}

1. Kontrol Atas Tabungan dan Pendapatan

Tabel berikut ini menyajikan perbandingan antara perempuan anggota BMT dan nonBMT atas kontrol terhadap tabungan dan pendapatan usaha.

Tabel 2 : Perbandingan antara Perempuan yang Menjadi Anggota BMT dan nonBMT atas Kontrol Terhadap Tabungan dan Pendapatan Usaha

\begin{tabular}{|c|c|c|c|c|c|c|}
\hline \multirow[b]{2}{*}{ Keterangan } & \multicolumn{2}{|c|}{ Responden } & \multicolumn{2}{|c|}{ Mean Rank } & \multirow{2}{*}{$\begin{array}{l}\text { Asymp. } \\
\text { Sig. (2- } \\
\text { tailed) }\end{array}$} & \multirow{2}{*}{$\begin{array}{c}\text { Mann } \\
\text { Whitney U } \\
\text { Test }\end{array}$} \\
\hline & $\begin{array}{l}\text { Anggota } \\
(100)\end{array}$ & $\begin{array}{l}\text { Non } \\
(50)\end{array}$ & Anggota & Non & & \\
\hline $\begin{array}{l}\text { Keputusan mengenai } \\
\text { Kepemilikan Tabungan }\end{array}$ & & & & & & \\
\hline a. Sendiri & $84(84 \%)$ & 27 & 77.50 & 71.00 & $0.00^{*}$ & 1750.000 \\
\hline b. Pasangan & $8(8 \%)$ & $(54 \%)$ & 82.00 & 62.50 & $0.04^{* *}$ & 1.850 .000 \\
\hline $\begin{array}{l}\text { c. Berdua dengan } \\
\text { pasangan }\end{array}$ & $8(8 \%)$ & $\begin{array}{r}13(0 \%) \\
10 \\
(20 \%)\end{array}$ & 75.25 & 63.00 & $0.02^{* *}$ & 2.175 .000 \\
\hline $\begin{array}{l}\text { Keputusan mengenai } \\
\text { penggunaan }\end{array}$ & & & & & & \\
\hline pendapatan dan & $51(51 \%)$ & & 81.25 & 64.00 & $0.008^{*}$ & 1925.000 \\
\hline keuntungan usaha & $8(5 \%)$ & & 76.00 & 74.00 & 0.3160 & 2450.000 \\
\hline a. Sendiri & $39(39 \%)$ & 14 & 76.00 & 71.00 & & 2175.000 \\
\hline b. Pasangan & & $(28 \%)$ & & & $0.042^{\star *}$ & \\
\hline $\begin{array}{l}\text { c. Berdua dengan } \\
\text { pasangan }\end{array}$ & & $\begin{array}{r}12 \\
(24 \%)\end{array}$ & & & & \\
\hline
\end{tabular}




\begin{tabular}{|c|c|c|}
\hline & & $\begin{array}{r}17 \\
(34 \%)\end{array}$ \\
\hline
\end{tabular}

Sumber: Pengolahan data primer dengan SPSS, 2015

Hasil pengujian Mann Whitney $U$ diperoleh nilai asymp.sig (2-tailed) dibawah 0.05 untuk seluruh item pertanyaan, sehingga $\mathrm{Ho}$ ditolak dan $\mathrm{Ha}$ diterima. Artinya perempuan yang menjadi anggota BMT memiliki kontrol lebih besar terhadap tabungan dan pendapatan usaha yang mereka kelola dibanding perempuan yang bukan anggota BMT. Pengujian Mann Whitney $U$ juga mengkonfirmasi adanya perbedaan signifikan pada kategori pengambilan keputusan sendiri, pasangan, bersama pasangan dan dengan orang lain terkait kontrol kepemilikan tabungan dan pemanfaatan keuntungan bisnis antara anggota BMT dan nonBMT. Lebih jauh, secara statistik laki-laki memiliki kontrol yang sangat rendah terhadap kepemilikan tabungan dan hasil usaha yang dilakukan oleh perempuan pelaku usaha mikro yang menjadi responden penelitian. Ini menunjukan perempuan cukup berdaya untuk mengambil keputusan sendiri terkait dengan hasil usahanya.

Hasil riset ini mendukung studi yang sebelumnya dilakukan oleh Kratzer dan Pato (2013) di Tanzania dimana partisipasi perempuan dalam lembaga keuangan mikro berdampak terhadap kontrol yang lebih tinggi pada tabungan dan pendapatan usaha dibanding mereka yang tidak terlibat dalam institusi keuangan mikro. Studi ini juga selaras dengan keyakinan Swain \& Wallentin (2008) bahwa perempuan yang aktif secara ekonomi dan memiliki tabungan pribadi akan berdampak pada penguatan daya tawar dalam keluarga karena kontribusinya terhadap pendapatan keluarga.
Hasil wawancara mendalam terhadap lima responden mendukung temuan tersebut. Seluruh responden menyatakan bahwa mereka memiliki keleluasaan dalam mengelola tabungan. Keputusan untuk menjadi anggota BMT dan mengakses sumber daya finansial juga merupakan inisiatif pribadi dalam upaya pengembangan usaha sebagaimana diungkapkan oleh responden berikut :

"Ya untuk tambahan modal, kan awal mulanya saya nggak pinjem cuma ikut nabung aja disana, tapi karena saat itu saya juga butuh modal, ya..meskipun cuma satu juta dari pada saya susah nyari juga ya akhirnya saya pinjam ke BMT. Dananya ya, gimana ya mbak kan lebih mudah to mbak buat muternya. Kalau untuk pendapatan tiap harinya, alhamdulillah saya kan orangnya tetep bersyukur ya seberapapun itu. Tapi insyaAllah sih tiap hari memang ada kemajuan. Kalau untuk aset insyaAllah memang tetap bertambah"

Diakui oleh responden, dalam pengelolaan keuntungan bisnis mereka tidak mendapatkan intervensi dari pasangan. Suami memberikan ruang untuk mengatur usaha yang telah dirintisnya.

"Ya..tetep saya sendiri mbak. Penggunaan keuntungan dari dagangan ini ya saya sendiri yang nggunain. Jadi gini mbak, kalau seorang ibu atau perempuan itu kalau punya pendapatan sendiri kan nggak harus tergantung suami mbak, yang ngurus kan juga saya sendiri terus kalau saya mau beli apapun juga hak say. Cuma gimana ya mbak suami itu kan tidak boleh terlalu ikut campurlah istilahnya, meskipun kita juga memikirkan kebutuhan rumahtangga, tapi kita kan punya hak juga, hak khususlah ya sebagai 
seorang ibu, tapi ya tetep ya mbak suami itu juga harus bertanggung jawab untuk keluarganya, Cuma kita sebagai perempuan terutama ibu ya mbak kita juga tetep harus mandirilah ya, jadi kalau ada kebutuhan yang mendadak kan nggak harus tergantung suami jadi kita bisa atasi sendiri"

\section{Kepemilikan}

Hasil pengujian Mann Whitney $U$ menunjukan adanya signifikasi perbedaan antara anggota BMT dan nonBMT dalam hal kepemilikan aset dan properti. Jenis aset yang secara legal formal dimiliki oleh perempuan didominasi oleh kepemilikan $\mathrm{Hp}$, televisi, rice cooker, kulkas dan kendaraan bermotor. Penguasaan perempuan atas aset yang bernilai ekonomis tinggi seperti tanah dan rumah masih terhitung rendah.

Tabel 3 : Perbandingan antara Perempuan yang Menjadi Anggota BMT dan nonBMT atas Kepemilikan Aset/properti

\begin{tabular}{|c|c|c|c|c|c|c|}
\hline \multirow[b]{2}{*}{ Keterangan } & \multicolumn{2}{|c|}{ Responden } & \multicolumn{2}{|c|}{ Mean Rank } & \multirow{2}{*}{$\begin{array}{l}\text { Asymp } \\
\text {. Sig. } \\
(2- \\
\text { tailed) }\end{array}$} & \multirow{2}{*}{$\begin{array}{c}\text { Mann } \\
\text { Whitney U } \\
\text { Test }\end{array}$} \\
\hline & $\begin{array}{c}\text { Anggota } \\
(100)\end{array}$ & Non (50) & Anggota & Non & & \\
\hline $\begin{array}{l}\text { Manakah properti } \\
\text { yang secara legal } \\
\text { formal menjadi }\end{array}$ & & & & & & \\
\hline milik Anda? & $51(51 \%)$ & $26(92 \%)$ & 77.25 & 62.00 & 0.800 & 2475.000 \\
\hline a. Radio & $70(70 \%)$ & 36 & 76.00 & 71.50 & $0.003^{* *}$ & 1950.000 \\
\hline b. Televisi & 84 (84\%) & $(72 \%)$ & 76.50 & 63.50 & 0.053 & 2400.000 \\
\hline c. Hp & 69 (69\%) & $40(80 \%)$ & 77.25 & 72.00 & $0.039^{\star *}$ & 1875.000 \\
\hline d. Rice cooker & $67(67 \%)$ & 31 (62\%) & 76.75 & 71.00 & $0.014^{\star *}$ & 1925.000 \\
\hline e. Kulkas & $16(16 \%)$ & $31(62 \%)$ & 76.50 & 65.00 & $0.015^{\star *}$ & 2100.000 \\
\hline f. Tanah & 19 (19\%) & $6(12 \%)$ & 75.00 & 71.00 & 0.158 & 2225.000 \\
\hline g. Rumah & $53(53 \%)$ & $5(10 \%)$ & 78.25 & 70.00 & $0.020^{* *}$ & 1775.000 \\
\hline $\begin{array}{l}\text { h. Kendaraan } \\
\text { bermotor }\end{array}$ & & $21(42 \%)$ & & & & \\
\hline
\end{tabular}

Sumber: Pengolahan data primer dengan SPSS, 2015

Penggalian informasi melalui wawancara mendalam memberikan temuan menarik, responden mengakui akses finansial dari BMT tidak saja berpengaruh terhadap penambahan modal usaha tetapi juga memperluas

kontribusi perempuan di rumah tangga berupa perbaikan atau renovasi tempat tinggal. Selain itu, jenis aset lain yang dikuasai oleh perempuan adalah dalam bentuk emas :
"Kalau asetnya ya di dagangan ini, kan tadi kaya yang saya bilang. Pinjam ke BMT untuk nambah modal jadi ya buat dagangan ini, tapi bisa nyelengi sithiksithik mbak buat renovasi rumah, apa anu saya kan tabungannya ada emas batangan gitu jadi nek ada apa-apa nanti ya dijual. Tapi ya memang banyak larinya ke dagangan buat nambah barang dagangan ini. Kalau beli barang-barang rumah yo wis campur ada yang dari sini ada yang dari pensiunannya bapak. 
Pendapatan perempuan yang dihasilkan dari kegiatan bisnis akan berimplikasi terhadap peningkatan daya beli mereka. Bertambahnya income memungkinan perempuan untuk melakukan pembelian barang sendiri, dimana hal tersebut sulit dilakukan sebelumnya baik karena faktor kemiskinan maupun tradisi (Chen, 2007). Akses terhadap lembaga keuangan dan kegiatan usaha juga mengakibatkan peningkatan kepemilikan aset rumah tangga.

Pengujian Mann Whitney U juga mengkonfirmasi adanya perbedaan signifikan pada kategori pengambilan keputusan sendiri, pasangan, bersama pasangan dan dengan orang lain terkait kontrol kepemilikan tabungan dan pemanfaatan keuntungan bisnis antara anggota BMT dan nonBMT.

\section{Pengambilan Keputusan}

Tabel 4 mendeskripsikan persentase dan hasil uji Mann Whitney $U$ dari responden anggota dan nonanggota BMT dalam tiga tingkatan pengambilan keputusan yakni pengambilan keputusan secara independen, oleh pasangan dan bersama-sama dengan pasangan.

Tabel 4 : Perbandingan Pengambilan Keputusan AntaraAnggota dan NonAnggota BMT

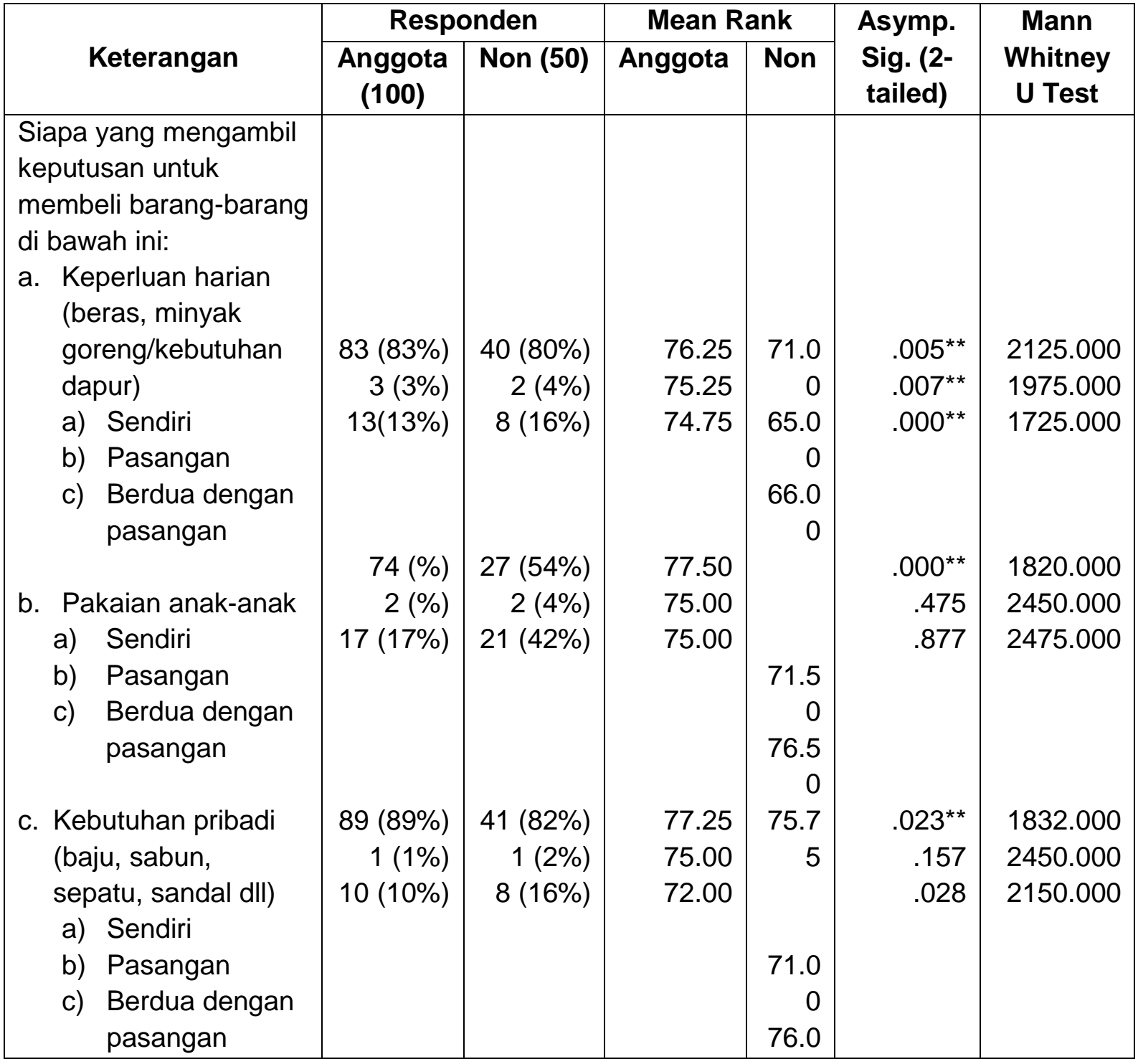




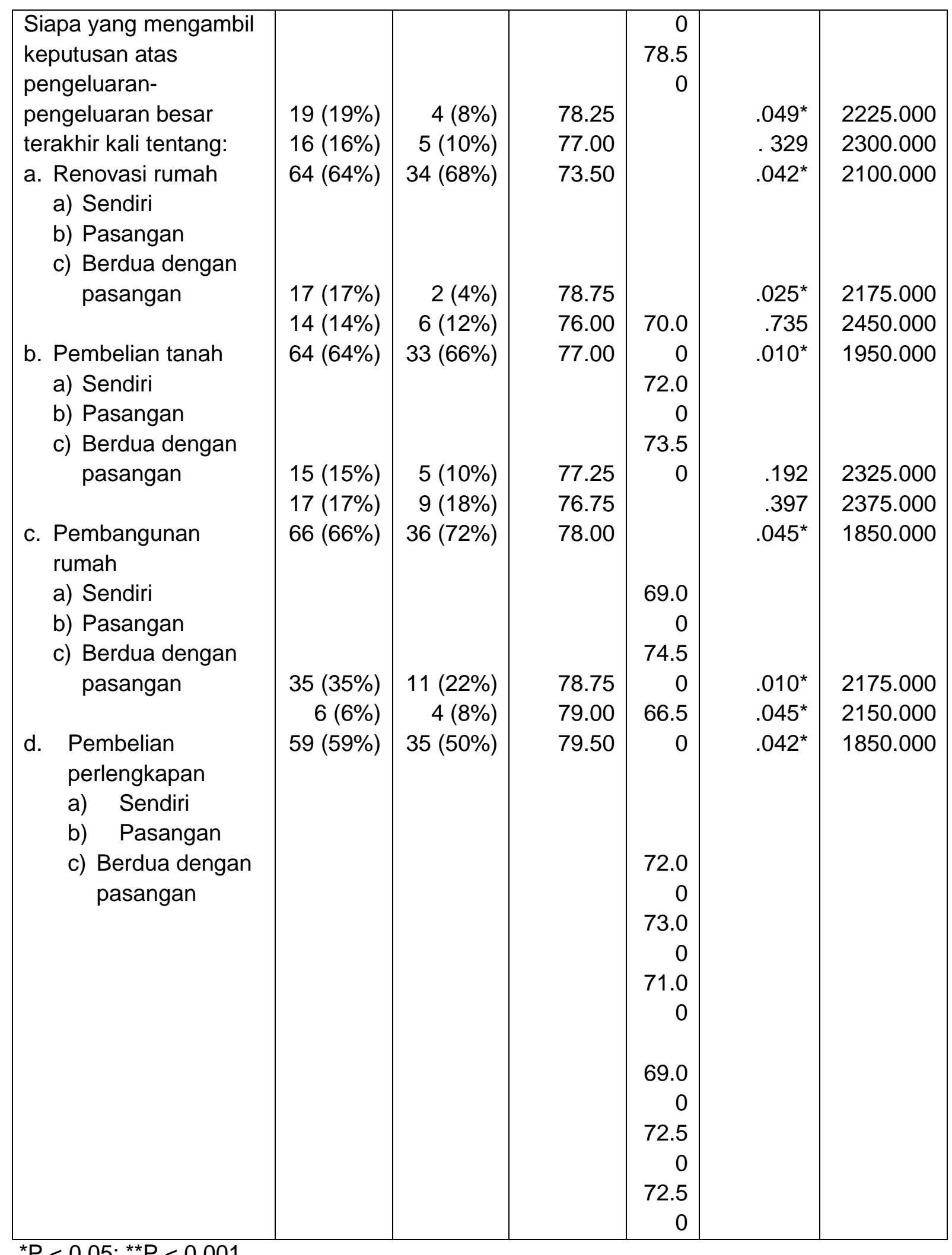

Sumber: Pengolahan data primer dengan SPSS, 2015

Pengujian secara statistik memperlihatkan terdapat perbedaan signifikan antara perempuan anggota
BMTdan nonanggota dalam tiga tingkatan pengambilan keputusan yakni oleh diri sendiri, pasangan, dan berdua dengan pasangan. Dari 21 item pertanyaan 
terdapat 8 butir yang tidak signifikan dengan nilai Asymp. Sig. (2-tailed) di atas 0.05 (Ho ditolak). Namun demikian mayoritas item memiliki nilai probabilitas di bawah 0,05 sehingga dapat dikatakan terdapat perbedaan nyata diantara keduanya. Artinya, perempuan anggota BMT lebih banyak mengambil peran dalam pengambilan keputusan di level rumah tangga dibanding perempuan yang tidak memanfaatkan layanan BMT.

Wawancara terkait isu tersebut juga menyiratkan temuan serupa, mayoritas responden mengakui jika pembelanjaan yang bersifat harian dan terhitung kecil dilakukan sendiri. Akan tetapi untuk pengeluaran besar lebih banyak hasil kesepatan berdua dengan pasangan.

"Pengambilan keputusan kalau untuk keperluan sehari-hari ya saya. Kalau yang besar ya berdua,hahahaha...jadi misalnya kalau beli sepeda motor ya kadangkadang saya ya kadang-kadang situ, nanti kompromi dulu kalau oke ya oke. Pokoknya kalau yang besar-besar ya harus berdua, tapi kalau cuma sehari-hari ya saya sendiri"

"Ya saya sendiri mbak, beli keperluan sehari hari ya saya sendiri to mbak, bapakkan sudah sepuh wis ora urusan jadi Cuma sekedar nyoh duit pensiunane. Anak-anak juga nggak ikut campur orang semua udah pada nikah tinggal anak saya satu ini yang mbantu dagang. Lha kalau pengeluaran yang besar-besar gitu saya rembugan antara saya bapak dan anakanak saya. Kaya kemarin saya abis renovasi rumah biayanya dua puluh lima juta itu juga rembugan sama bapak. Saya bilang Pak kan bentar lagi udah mau ujan terus gini..gini..catnya juga udah mau nglotok gini..gini..gini..seperti gitu ya saya rembugan. Kan ngecat plafon juga mbak udah pada bocor, kan udah dari dulu. Bapak pensiun tahun 1997 terus untuk mbangun rumah, kan tahun 1997 kan udah lama juga to mbak jadi plafonnya udah pada itu terus diganti. Nah...untuk proses rembugannya biasanya saya ngomong dulu ke bapak kalau disetujui baru cari tukangnya"

\section{Self-Efficacy}

Hasil pengujian Mann Whitney $U$ diperoleh nilai asymp.sig (2-tailed) sebesar 0.298 atau di atas 0,05 sehingga Ho diterima dan Ha ditolak. Artinya tidak ada perbedaan self efficacy antara perempuan yang menjadi anggota BMT dan perempuan nonanggota BMT.

Tabel 5 : Perbandingan responden Anggota BMT dan NonBMT pada SelfEfficacy

\begin{tabular}{|c|c|c|c|c|c|c|}
\hline \multirow[b]{2}{*}{ Keterangan } & \multicolumn{2}{|c|}{ Responden } & \multicolumn{2}{|c|}{ Mean Rank } & \multirow{2}{*}{$\begin{array}{l}\text { Asymp } \\
\text {. Sig. } \\
(2- \\
\text { tailed) }\end{array}$} & \multirow{2}{*}{$\begin{array}{l}\text { Mann } \\
\text { Whitney } \\
\text { U Test }\end{array}$} \\
\hline & $\begin{array}{c}\text { Anggota } \\
(100)\end{array}$ & Non (50) & Anggota & Non & & \\
\hline $\begin{array}{l}\text { Dengan siapa Anda bisa } \\
\text { berinteraksi secara } \\
\text { bebas/leluasa? }\end{array}$ & $76(76 \%)$ & $34(68 \%$ & 77.5 & 71,5 & .298 & 2300.000 \\
\hline
\end{tabular}

${ }^{*} \mathrm{P}<0.05 ;{ }^{* *} \mathrm{P}<0.001$

Sumber: Pengolahan data primer dengan SPSS, 2015 
Dengan demikian hasil pengujian ini berbeda dengan studi Kato dan Kratzer (2013) yang membuktikan secara empiris terdapat perbedaan self efficacy diantara keduanya. Secara teoritis, akses perempuan terhadap layanan lembaga keuangan mikro akan berkorelasi terhadap pemberdayaan ekonomi dimana hal ini membantu perempuan untuk merubah persepsi terhadap dirinya sendiri dan persepsi orang lain terhadap mereka. Rasa percaya diri akan terangkat ketika mereka mampu menjalankan kegiatan bernilai ekonomi dan dapat mengambil keputusan sendiri terkait manajemen usaha. Hunt dan Kasynathan (2001) menyebutkan jika hal yang sangat berarti bagi perempuan ketika menjadi anggota lembaga keuangan mikro adalah meningkatnya wawasan, rasa percaya diri, dan ketrampilan yang mereka peroleh setelah mendapatkan berbagai pelatihan yang diselenggarakan oleh lembaga keuangan mikro. Insignifikasi variabel self efficacy antara anggota dan bukan anggota BMT dalam riset ini diduga karena faktor ketiadaan layanan training, motivasi dan advokasi yang terkait dengan program pemberdayaan perempuan oleh lembaga keuangan mikro syariah sehingga tidak perpengaruh terhadap self efficacy responden.

Sebagaian besar responden penelitian menyatakan dapat berinteraksi secara bebas dan leluasa hanya kepada keluarga dan pasangan. Namun, interaksi dengan tetangga, teman di luar keluarga inti, pemimpin komunitas lokal (kepala desa, ketua PKK dII), dan orang-orang di pasar hanya bersifat sebatas keperluan. Perempuan masih berjarak dengan penentu kebijakan tingkat lokal seperti tokoh masyarakat atau kepala desa. Kercayaaan diri yang rendah dan khawatir membuat kesalahan menjadi faktor penyebab hambatan komunikasi. Hasil penulusuran melalui wawancara menguatkan dugaan tersebut,

"Ya sama anak-anak semuanya, yang jauh tu anak yang nomer empat karena jauh rumahnya udah punya keluarga sendiri juga. Tapi kalau rasan-rasan gitu ya sama bapak aja ya pokoknya berdua sama bapak. Nek tetangga ya nggak wong tetanggaku jauhjauh mbak, tetanggaku juga usaha-usaha semua jadi pada nggak ada waktu. Sama kepala desa juga nggak, mboten nate melibatkan mbak, takut aku nanti ndak ada yang salah. Kalau sama orang pasar ya ada misalnya sama ini (tetangga depan kios) deket banget, kalau misalnya nggak ada uang ya tulung utangi yo, yaudah saya kasih gitu-gitu udah biasa gitu, tapi nek nggak akrab ya nggak mau saya nanti ndak kliru"

\section{Self-Esteem}

Tabel 6 menerangkan bahwa secara statistik tidak ada perbedaan self esteem yang signifikan antara anggota dan nonanggota BMT.

Pengujian MannWhitney $U$ menunjukan seluruh dimensi pertanyaan memiliki angka Asymp. Sig. (2-tailed) diatas 0,05. Dengan demikian studi ini tidak sejalan dengan riset Hunt \& Kasynathan (2001) ; Kato \& Kratzer (2013) yang mengatakan jika keterlibatan perempuan dalam lembaga keuangan mikro akan meningkatkan self esteem dan self efficacy yang akan mendorong peran aktif mereka dalam dalam proses pengambilan keputusan di level rumah tangga dan komunitas

Tabel 6 Perbandingan Self Esteem Responden Anggota dan NonBMT

\begin{tabular}{|c|c|c|c|c|c|c|}
\hline \multirow[b]{2}{*}{ Keterangan } & \multicolumn{2}{|c|}{ Responden } & \multicolumn{2}{|c|}{ Mean Rank } & \multirow{2}{*}{$\begin{array}{l}\text { Asymp. } \\
\text { Sig. (2- } \\
\text { tailed) }\end{array}$} & \multirow{2}{*}{$\begin{array}{c}\text { Mann } \\
\text { Whitney } \\
\text { U Test }\end{array}$} \\
\hline & $\begin{array}{c}\text { Anggota } \\
(100)\end{array}$ & Non (50) & Anggota & Non & & \\
\hline
\end{tabular}




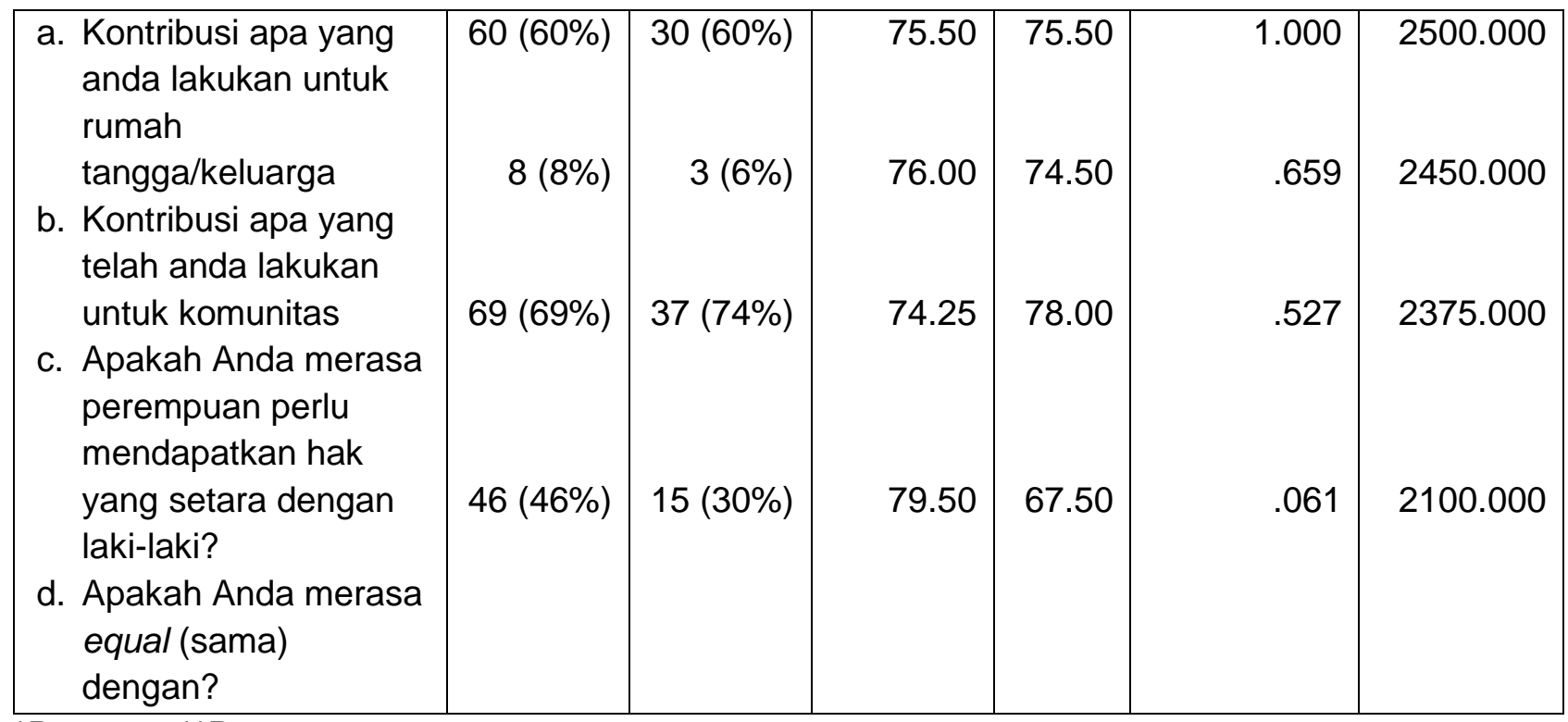

${ }^{*} \mathrm{P}<0.05 ;{ }^{* *} \mathrm{P}<0.001$

Sumber: Pengolahan data primer dengan SPSS, 2015

Dimensi kontrol merupakan aspek yang paling umum digunakan untuk mengukur pemberdayaan perempuan selain sumber daya, agency, achievement (pencapaian) dan akses. Cheston \& Khun (2002), ukuranukuran kunci pemberdayaan yang lain seperti pengambilan keputusan, kepercayaan diri dan self-esteem adalah sangat sulit untuk diukur secara obyektif. Lembaga keuangan mikro akan mendorong independensi perempuan secara ekonomi melalui penguasaan sumber daya modal dan keuangan. Lebih lanjut, kemandirian ekonomi akan berbanding lurus dengan peningkatan bargaining power di tingkatan keluarga dan komunitas yang pada akhirnya akan berpengaruh terhadap kenaikan prestige dan self esteem.

Studi yang dilakukan oleh The International Fund for Agricultural Development (IFAD) terkait dengan dimensi pemberdayaan perempuan seperti kemampuan untuk mengambil keputusan, kepercayaan diri dan self

esteem mengindikasikan bahwa perempuan mampu membuat keputusan terkait spending dari income yang mereka hasilkan, mengartikulasikan pandangan serta perhatian terhadap isu rumah tangga dan komunitas.
Akan tetapi, peningkatan rasa percaya diri dan self esteem secara khusus akan muncul apabila mereka telah mengikuti training mengenai hak asasi perempuan secara sosial dan politik (Kay, 2003). Studi lain menunjukan bahwa self-Help Group (SHGs) yang dimediasi oleh lembaga keuangan mikro membantu meningkatkan kontrol perempuan terhadap aset, pencapaian self esteem, pengetahuan dan juga power (Zaman 2001; Simanowitz and Walker 2002).

Secara khusus BMT juga tidak memiliki program pemberdayaan perempuan meskipun mayoritas anggota BMT adalah perempuan pedagang pasar atau pengusaha mikro yang berlokasi di sekitar BMT. Terlebih lagi, BMT tidak memfasilitasi kegiatan pelatihan, penguatan usaha dan peningkatan kapasitas bagi para anggotanya. Konsekuensinya, kontribusi perempuan terhadap pembangunan komunitas berupa keterlibatan dalam aksi protes terhadap peristiwa yang berdampak buruk terhadap masyarakat, pengambilan peran terhadap kepemimpinan lokal dan penyelesaian konflik sosial tidak terbangun secara maksimal seperti terekam dalam petikan wawancara berikut :

"InsyaAllah saya aktif mbak, kebetulan saya itu ibu dukuh. Jadi walaupun ada undangan 
jam delapan pun saya bisa mbak, kadang kalau di desa ada manten jam tujuh nanti saya ke pasar dulu buka warung aja nanti ada yang mbantuin jual terus saya ke tempat manten, kadang saya memang libur kalau dari pagi saya harus ke tempat tetangga yang punya hajatan mbak. Kalau konflik kan nggak pernah mbak, tapi kalau protes gitu saya sama bapak lebih baik diam kan saya sama bapak nggak boleh terlalu banyak ngomong kalau di desa, jadi kita itu hanya sebatas aktif mengikuti kegiatan gitu mbak tapi nggak terlalu ikut andil yang lebih dalam jadi memang bapak yang juga membatasi kalau kita terlalu aktif kan juga nggak baik buat kita nanti keluarganya juga gimana".

\section{Mobilitas dan partisipasi dalam kegiatan di luar rumah}

Tabel di bawah ini memperlihatkan perbandingan mobilitas dan partisipasi dalam kegiatan di luar rumah antara perempuan anggota dan nonBMT. Pengujian Mann Whitney $U$ memberikan menunjukan terdapat perbedaan mobilitas yang signifikan antara perempuan anggota BMT dan nonBMT, diindikasikan dari angka Asymp. Sig. (2-tailed) sebesar 0.047 atau di bawah $5 \%$ sehingga masuk wilayah penolakan Ho

Tabel 7 :Perbandingan Mobilitas dan Partisipasi Responden Anggota dan NonBMT

\begin{tabular}{|l|c|c|r|r|r|r|}
\hline \multirow{2}{*}{ Keterangan } & \multicolumn{2}{|c|}{ Responden } & \multicolumn{2}{c|}{ Mean Rank } & $\begin{array}{c}\text { Asymp. } \\
\text { Sig. (2- } \\
\text { tailed) }\end{array}$ & $\begin{array}{c}\text { Mann } \\
\text { Whitney U } \\
\text { Test }\end{array}$ \\
\cline { 2 - 7 } & $\begin{array}{c}\text { Anggota } \\
(\mathbf{1 0 0 )}\end{array}$ & Non (50) & $\begin{array}{c}\text { Anggot } \\
\text { a }\end{array}$ & Non & & \\
\hline $\begin{array}{l}\text { a. Pernahkah } \\
\text { anda pergi ke } \\
\text { tempat berikut ini } \\
\text { sendiri? }\end{array}$ & $65(65 \%)$ & $17(34 \%)$ & 71.50 & 83.50 & .047 & 2100.000 \\
$\begin{array}{l}\text { b. Pernahkan } \\
\text { Anda berpartisipasi } \\
\text { dalam kegiatan? }\end{array}$ & $78(78 \%)$ & $16(32 \%)$ & 78.25 & 71.00 & .038 & 2175.000 \\
\hline
\end{tabular}

Sumber: Pengolahan data primer dengan SPSS, 2015

Wawancara mendalam dalam riset ini menguatkan hasil uji statistik tersebut, responden menyatakan mereka telah

terbiasa melakukan mobilitas pribadi tanpa harus bergantung pada orang lain

atau pasangan meskipun untuk acara-acara tertentu hadir bersama dengan suami;

"Saya sendirian, kalau dateng ke undangan kecamatan atau mana gitu kalau undangannya suruh dateng sendiri ya saya dateng sendiri mbak. Kalau ngurus suratsurat gitu ya sama bapak kan nanti sekalian bapak ke kantor. Tapi sebenarnya saya berani sendiri mbak, jadi kan saya pernah ada masalah ya mbak jadi sebelumnya kan saya tinggal sendiri pas itu ada masalah terus saya ngurus sendiri, saya ke pengadilan sendiri saya berani terus di kantor capil sendiri. Selain itu kalau ada pendampingan atau kayak kemarin ada diklat di SMK itu saya dateng sendiri berani, bahkan sampai saat ini kan masih ada pendampingan dari Provinsi gitu saya juga dateng sendiri. Kalau bareng bapak paling kalau ada undangan berdua sih mbak kaya kondangan, silaturahim, atau njenguk orang sakit"

Sementara itu, partisipasi perempuan anggota BMT dalam berbagai kegiatan di luar rumah secara statistik juga berbeda dengan nonanggota BMT. Ini terlihat dari angka Asymp. Sig. (2-tailed) sebesar 0.038 atau di bawah 5\% sehingga masuk wilayah penolakan Ho. Hal ini juga diakui oleh responden dalam sesi wawanca berikut ini: 
"Ikut, pameran di Kabupaten pernah di Kecamatan juga pernah. Pamerannya apa yang saya pamerankan itu? Itu adalah bakat saya sendiri tas manik-manik. Bikin sendiri, tapi memang mahal harganya, paling rendah itu Rp 138.000 sampai harga Rp 180.000. itu pamerannya disuruh dari Kabupaten dikasih modal juga, kalau dari kecamatan biasanya minta "Bu..bikin tas ini, model ini, model yang bumbung, model tas kantor" ya udah aja, kecamatan juga dikasih modal"

\section{KESIMPULAN DAN SARAN}

Penelitian ini menghasilkan beberapa temuan antara lain 1) Secara statistik terdapat perbedaan signifikan kontrol tabungan dan pendapatan usaha, pengambilan keputusan, mobilitas dan partisipasi antara perempuan yang menjadi anggota BMT dan nonBMT. 2) Hasil pengujian Mann Whitney $U$ menunjukan tidak ada perbedaan self efficacy dan self esteem antara perempuan yang menjadi anggota BMT dan perempuan nonanggota BMT.

Riset merekomendasika beberapa hal yakni 1) Penelitian berikutnya perlu menambah jumlah minimal responden sehingga temuan penelitian lebih mewakili situasi yang sebenarnya. 2) Segmen terbesar dari BMT adalah pedagang atau pengusaha mikro perempuan. Oleh karena itu, adalah penting bagi BMT untuk memiliki programprogram yang berorientasi pada pemberdayaan perempuan. 3) Penelitian berikutnya perlu melihat bagaimana dampak BMT terhadap relasi gender dalam rumah tangga dan implikasinya terhadap perempuan. Hal ini penting mengingat dalam kultur masyarakat Indonesia khususnya Yogyakarta, praktek-praktek patriarkhis masih cukup kuat berakar.

\section{UCAPAN TERIMAKASIH}

Tim peneliti mengucapkan banyak terimakasih kepada Direktorat Penelitian dan Pengabdian Masyarakat Universitas Islam Indonesia yang telah membiayai penelitian ini dalam skema penelitian madya. Selain itu timpeneliti juga mengucapkan terimakasih pada pihak-pihak yang telah membantu dalam pelaksanaan penelitian ini.

\section{DAFTAR PUSTAKA}

Aseanty \& Hasan. (2013). Islamic Microfinance, Socio-economic Wellbeing of Women and Their Families in Bangladesh. International Journal of Banking and Finance, Vol. 7, Iss. 1 [2010], Art. 7

Barnes, C., Keogh, E., \& Nemarundwe, N. (2001). Microfinance Program Clients and Impact: An Assessment of Zambuko Trust, Zimbabwe. Washington, DC: Management Systems International.

Chen, M.A., R. Jhabvala, R. Kanbur, N. Mirani, K. Osner and C. Richards, eds. (2007) Membership-based organizations of the poor. London: Routledge.

Haryadi, Didi. (2014). Masa Depan BMT Makin Cerah, 14 Juni, 2014, diakses online tanggal 5 Desember 2014 dari www.inilahkoran.com

Hunt, J., \& Kasynathan, N. (2001). Pathways to empowerment? Reflections on microfinance and transformation in gender relations in South Asia. Gender \& Development, 9(1), 42-52.

Kato \& Kratzer. (2013). "Empowering Women through Microfinance: Evidence from Tanzania." ACRN Journal of Entrepreneurship Perspectives, Vol. 2, Issue 1, p. 3159, Feb. 2013 ISSN 2224-9729

Kay, T. (2003) Empowering women through self-help micro-credit programmes. Bangkok:Gender and Development Section, Emerging Social Issues Division, United Nations Economic and Social Commission for Asia and the Pacific (ESCAP).

Kahn, Rana Ejaz Ali \& Noreen, Sara (2012). "Microfinance and Women empowerment: A case study of District Bahawalpur (Pakistan)." 
African Journal of Business Management, Vol. 6:12, pp. 4514 -- 4521

Kabeer, N. (2001). Conflicts over Credit: ReEvaluating the Empowerment Potential of Loans to Women in Rural Bangladesh. "World Development," 29 (1), 63-84.

Kuncoro, Mudrajad. (2003). Metode Riset Untuk Bisnis \& Ekonomi. Jakarta: Erlangga

Mayoux, L. (1999). Research Round-Up Women's empowerment and microfinance programmes: Strategies for increasing impact. "Development in Practice," 8(2), 235-241.

Mahmud, S. (2003). Actually How Empowering is Microcredit? Development and Change, 34(4), 577-605.

Malhotra, Anju dan Schuler (2002) Measuring Women's Empowerment as a Variable in International Development, Background Paper Prepared for the World Bank Workshop on Poverty and Gender: New Perspectives.
Nugroho, Riant, Dr. (2008) Gender dan Strategi Pengarus-utamaanya di Indonesia. Pustaka Pelajar. Yogyakarta

Pitt, M. M., \& Khandker, S. R. (1998). The Impact of Group-Based Credit Programs on Poor Households in Bangladesh: Does the Gender of Participants Matter? Journal of Political Economy, 106(5), 958.

Prijono \& Pranarka. (1996). Pemberdayaan: Konsep, Strategi dan Implementasi, CSIS, Jakarta

Zaman, H. (2001) Assessing the poverty and vulnerability impact of micro-credit in Bangladesh: a case study of BRAC. Background paper for World Bank WorldDevelopment Report 2000/2001. Washington, DC: World Bank. (unpublished) 